Referencia para citar este artículo: Escobar-García, B. \& Hincapié-García, A. (2017). DAR LA PALABRA. En torno al lenguaje de los niños y las niñas en la cárcel. Revista Latinoamericana de Ciencias Sociales, Niñez y Juventud, 15(1), pp. 59-70.

\title{
DAR LA PALABRA. En torno al lenguaje de los niños y las niñas en la cárcel ${ }^{*}$
}

\author{
BIBIANA ESCOBAR-GARCÍA** \\ Directora de Investigaciones Universidad Autónoma Latinoamericana, Colombia. \\ AleXÁNDER HinCAPIÉ-GARCÍA ${ }^{* * *}$ \\ Profesor Universidad de San Buenaventura, Colombia.
}

Artículo recibido en febrero 26 de 2016; artículo aceptado en abril 8 de 2016 (Eds.)

Hurbinek, que tenía tres años y probablemente había nacido en Auschwitz, y nunca había visto un árbol; Hurbinek, que habia luchado como un hombre hasta el último suspiro, por conquistar su entrada en el mundo de los hombres, del cual un poder bestial lo había exiliado; Hurbinek, el sinnombre, cuyo minúsculo antebrazo había sido firmado con el tatuaje de Auschwitz; Hurbinek murió en los primeros días de marzo de 1945, libre pero no redimido. Nada queda de él: el testimonio de su existencia son estas palabras mías

Primo Levi, 2012

- Resumen (descriptivo): este trabajo es parte de la investigación, los cuerpos de la excepción. Maternidad e infancia en la cárcel. Corresponde al referente teórico de una categoría vinculada al desarrollo del lenguaje de los niños en la institución carcelaria. El supuesto básico señala las condiciones de empobrecimiento del lenguaje en las cárceles y lo vincula a la suspensión antropológica mediante la cual allí se procede. Se asume que si bien la función habitual que se imagina para el sistema carcelario es la de normalizar a los sujetos, esta función da lugar a una más económica: proteger a la sociedad de los desechos antropológicos que repetidamente produce la Modernidad en el presente. No obstante, dicha protección sacrifica las condiciones de posibilidad de los niños que en la cárcel comparten la condena de sus madres.

Palabras clave: infancia, lenguaje, antropología, pedagogía, cárcel (Tesauro de Ciencias Sociales de la Unesco).

\section{GIVING THE WORD. Children's language in jail}

- Abstract (descriptive): This paper is based on the research study titled The bodies who are part of the exception: Maternity and childhood in jail. Specifically, it corresponds to the theoretical

\footnotetext{
* Este artículo de reflexión hace parte del proyecto terminado "Los cuerpos de la excepción. Maternidad e infancia en la cárcel", financiado por la Universidad Autónoma Latinoamericana y la Universidad de San Buenaventura. Está identificado con el Código: FT-INV-O12. El acta de inicio se firma en octubre del 2014 y la de cierre se firma el 19 de febrero del año 2016 y se identifica con el código INPR. 01. V1. El artículo se inscribe en las ciencias de la educación como área de conocimiento y puede considerarse como un trabajo de pedagogía general.

** Doctora en Filosofía de la Universidad Pontificia Bolivariana. Directora General de Investigaciones, Universidad Autónoma Latinoamericana. Correo electrónico: bibiana.escobar@unaula.edu.co

*** Doctor en Educación de la Universidad de Antioquia. Becario de Colciencias. Docente titular de la Facultad de Educación, Universidad de San Buenaventura (seccional, Medellín). Correo electrónico: alexdehg@yahoo.es
} 
construction of a category related to the development of children's language within a correctional institution. The basic assumption indicates the conditions of language's impoverishment in prisons, linking it to the anthropological suspension caused by imprisonment. The original function of the prison system was to normalize and rehabilitate subjects, yet this idea has led to another function that is economic: to protect society from the anthropological waste produced by modernity. However, this protection sacrifices the conditions of possibility for children in jail who share their mothers' conviction.

Key words: childhood, language, anthropology, pedagogy, jail (Unesco Social Sciences Thesaurus).

\section{$D A R$ A PALABRA. Em torno da linguagem das crianças na prisão}

- Resumo (descritivo): O trabalho aqui apresentado é parte da pesquisa: Os corpos da exceção. Maternidade e infância na cadeia. Em particular, corresponde à construção teórica de uma categoria ligada ao desenvolvimento da linguagem das crianças no seio da instituição da prisão. O pressuposto básico designa as condições de empobrecimento da linguagem nas prisões e faz ligação à suspensão antropológica por meio do que acontece lá. Presume-se que, se a função usual que é imaginada para o sistema prisional é normalizar aos sujeitos, essa função gerou um lugar mais econômico: proteger a sociedade de detritos antropológicos que produz repetidamente a Modernidade no presente. Contudo, essa protecção sacrifica as condições de possibilidade das crianças que na prisão compartilham a convicção de suas mães.

Palavras-chave: infância, linguagem, antropologia, pedagogia, prisão (Thesaurus de Ciências Sociais da Unesco).

-1. Introducción. -2. Contextualización del problema. -3. Antropología pedagógica e infancia. -4. Lenguaje y encierro. -5. Resultados y conclusiones. -Lista de referencias.

\section{Introducción}

Este artículo está asociado a la investigación terminada Los cuerpos de la excepción. Maternidad e infancia en la cárcel. El trabajo de campo se realizó en el Complejo Carcelario y Penitenciario Pedregal -Coped Medellín. La población con la cual se intervino, es decir, las madres y sus hijos encarcelados, tuvo una variabilidad entre doce y quince mujeres e igual número de niños $\mathbf{y}$ niñas. El enfoque de la investigación se puede denominar hermenéutico-reconstructivo. Por ello se entiende un trabajo autoreflexivo $\mathbf{y}$ crítico que supera la interpretación ingenua (Prior-Olmos, 2002). Es decir, el enfoque hermenéutico-reconstructivo se constituye en un tipo de conocimiento con dos aspiraciones de validez. La primera es teórica y, por lo mismo, universal. Se asume que el cometido de la teoría no es particularizar sino elevar sus postulados al registro de lo universal y necesario, para decirlo con Kant (2006). La segunda aspiración es hipotética y empírica. Esto supone que la teoría depende de los datos, aunque no se reduce a ellos. Por lo cual, lo hipotético y lo empírico son acercamientos directos a la vida social. Las técnicas investigativas utilizadas fueron el diario de campo, la observación participante, la entrevista a profundidad, la crítica sistemática y permanente de los datos encontrados mediante su triangulación- y la saturación de las categorías. Estas técnicas se pusieron en función de una comparación constante entre teoría y datos. El propósito central consistió en ampliar lo teórico desde los datos. En síntesis, se está señalando que el interés no ha sido el de presentar una descripción sumaria de la institución carcelaria, sino el de aportar a la discusión de los instrumentos teóricometodológicos usados para analizar el problema planteado.

Siguiendo a Agamben (2006), el supuesto principal de la investigación informa que el preso es una figura animal con rasgos humanos. Esa fisonomía animal, formada con las 
particularidades políticas del mundo moderno, esa fisonomía sostenida por el derecho, tiene una función social económica. Dicha función es la de señalar un límite antropológico que separa lo humano de lo inhumano, teniendo presente que solo la vida humana, es decir, la que ha sido reconocida como tal, merece ser vivida ${ }^{1}$. El preso constituye lo exterior en el interior de lo antropológicamente reconocible. Está recluido en una zona de suspensión antropológica. Esto quiere decir que el hombre produce al hombre, mediante criterios de separación y exclusión.

En este sentido, la infancia y la maternidad no son exclusivamente un período evolutivo y una función natural, sino dos determinaciones históricas producidas socialmente, y por ello están sometidas a decisiones que escapan a la voluntad del sujeto. Ariès (1987) demuestra que la infancia no es lo mismo que los niños -si por ello se entiende la 'criatura humana'-. Bastante escasa a lo largo de la historia, la infancia es una sensibilidad que se consolida entre los siglos XVIII y XIX como parte de los valores burgueses. Para Latinoamérica, Pedraza (2007) indica que esta sensibilidad se administra con criterios raciales, lo que implica que no para todos los niños puede actuar como recurso de protección. Por su parte, la maternidad, lejos de ser definida como una función natural (Badinter, 1981), hay que concebirla como parte de la producción y reproducción social de la heterosexualidad, separando, por ejemplo, la maternidad deseable -en términos de raza y clase social- de la maternidad desechable. Para decirlo de otra manera, a través de la maternidad se aseguran los recursos para que las sociedades occidentales confirmen la heterosexualidad como una obligación de la que depende la familia y el orden simbólico.

Con respecto al avance que se presenta en este artículo, el supuesto se liga al desarrollo del lenguaje de los niños dentro de la institución carcelaria. Subraya el empobrecimiento del lenguaje y lo vincula con la suspensión antropológica que la cárcel instituye. Basados en Vygotski (1996), es posible sostener que las relaciones del hombre consigo mismo, con los otros, con el mundo y con los objetos, no

1 Esto tiene su revés: si hay vidas que merecen ser vividas, hay vidas que no merecen vivirse (Agamben, 2010a).

Rev.latinoam.cienc.soc.niñez juv 15 (1): 59-70, 2017 http://revistalatinoamericanaumanizales.cinde.org.co DOI: $10.11600 / 1692715 \times .1510226022016$ son la expresión de meros reflejos empíricos. Al contrario, son relaciones creadoras que solamente son posibles a través del lenguaje. Por lo mismo, lo más significativo que el hombre crea se desprende de las posibilidades que el lenguaje le dona. De este modo, es prioritario preguntarse cuál es la deuda que tienen las sociedades con aquellos niños a los que se les ofrece las condiciones empobrecidas para el desarrollo de su lenguaje. Esto es, cuál es la responsabilidad moral con la otra infancia -la que se forma en el encierro-.

\section{Contextualización del problema}

La discusión sobre las cárceles no es nueva. Para Toro-Vanegas (2007), Colombia regula su sistema penitenciario a comienzos del siglo XX reiterando la necesidad de castigar la violación de la ley. Solamente en 1963 se establece que el fin de la cárcel es la rehabilitación y la resocialización más no el castigo. Con esto se quiere desplazar la idea de la justicia como venganza para concebirla en términos de adaptación social. Ya con la Constitución de 1991 se ratifica lo expresado en 1963, aunque afirmando un nuevo criterio, a saber: el fin último de la pena tiene que ser la reincorporación armoniosa del delincuente a la sociedad. El término armonioso tiene un tono humanista que se ocupa del delincuente pero no de la cárcel como institución social ${ }^{2}$.

Foucault (1982) le hace una mиесa al humanismo que se adueña del preso. El humanismo, lejos de significar un serio y radical cuestionamiento al sistema penitenciario, termina por reforzarlo. Es necesario establecer que reclamar la incorporación de reformas para habilitar mejores condiciones destinadas al preso, sin detenerse a problematizar el sistema que establece la cárcel como lugar de corrección, no es otra cosa que prolongar el poder que puede decidir sobre el encierro de los hombres. Es decir, el humanismo no cuestiona el porqué de la cárcel sino el porqué de sus condiciones. Subyace a cualquier buena intención de reforma, lo que es un recurso para relanzar la vigencia del sistema penitenciario

$2 \quad$ Para un análisis reciente sobre la situación penitenciaria, se recomienda el trabajo de Ossa-López (2016) 
mediante su transformación, pero sin cuestionar la violencia que está a la base de dicho sistema.

La situación sustantiva es clara: las cárceles no son otra cosa que la crisis de su funcionamiento. Cabe preguntarse, como lo hace Foucault (1982), qué tipo de sociedades son aquellas que las reclaman como manifestación del poder de gobernar, cuando de las cárceles puede afirmarse no la voluntad por crear condiciones para el hombre, sino su capacidad para redoblar la destrucción que, previamente, ha expulsado determinadas vidas y distintos cuerpos al encierro. Por lo tanto, el endurecimiento de las penas, solicitud que no cesa cuando se gobierna gestionando la percepción de inseguridad, desnuda el fracaso del Estado con respecto a la justicia, de sus instituciones para crear condiciones para la vida y de la sociedad civil por su inclemente reclamo de más castigo. En esta misma dirección, Martyniuk afirma que: "La cárcel es un torbellino que se impone sobre unos cuerpos para dejar sobre seguro a otros. Engaño y resignación administrados" (Martyniuk, 2011, pp. 219-220). Por contradictorio que parezca, las cárceles no son expresión de la seguridad de una sociedad, sino la afirmación de la peligrosidad en la que ha caído la vida social, sobredeterminada por una política reducida al derecho (Benjamin, 2010, Foucault, 2002a y Agamben, 2010b).

En Colombia se ha discutido la situación de las cárceles -abandono, hacinamiento, epidemias, imposibilidad de redimir las penas y violación de derechos-. Iván Cepeda-Castro enfatiza que esta no es una situación ocasional o temporal. La Corte Constitucional así lo ha reconocido. Por lo cual se entiende que dicha situación es estructural y corresponde con "(...) un estado de emergencia permanente, de violación continua de todos los Derechos Humanos, un estado de emergencia endémico que se intenta reparar a través de paños de agua tibia, que se intenta suturar en algunas de sus múltiples heridas" (Cepeda-Castro, 2012, p. 18). En otras palabras, CepedaCastro está diciendo que la situación puede entenderse como un 'estado de excepción' -Ausnahmezustand- que, en el caso de los más vulnerables y tal como sostenía Benjamin
(2012), se constituye en la norma. El 'estado de excepción' es una figura singular del derecho con la cual, paradójicamente, éste se suspende a sí mismo, dando paso al ejercicio de un poder en la forma de la soberanía. Dicho de otra manera, 'el estado de excepción' es el recurso político mediante el cual se implanta el orden entre los más vulnerables. Con el 'estado de excepción' el uso de las libertades individuales se sacrifica en función, por ejemplo, del performativo reclamo de protección y seguridad (Agamben, 2014).

Durante el siglo XX, el 'estado de excepción' no es la respuesta a peligros reales que amenazan el porvenir de las naciones. El 'estado de excepción' responde más al abigarrado placer de declararlo que a la posibilidad de contener peligro alguno. Es por ello que en la historia política de Alemania, Agamben (2010a) encuentra que Auschwitz, La Solución Final y, en general, el Tercer Reich, no hubieran sido posibles sin la figura del 'estado de excepción' o, más preciso, de un querido 'estado de excepción'. Así, el campo de concentración no resulta una extraña anécdota política, sino que puede pensarse como la consecuencia lógica de un 'estado de excepción' convertido en norma.

En Colombia se habla de 'Estado de Conmoción Interior' para connotar lo que se ha venido desbrozando. El capítulo $\mathrm{V}$ de la Constitución informa lo siguiente:

Artículo 213. En caso de grave perturbación del orden público que atente de manera inminente contra la estabilidad institucional, la seguridad del Estado, o la convivencia ciudadana, y que no pueda ser conjurada mediante el uso de las atribuciones ordinarias de las autoridades de Policía, el Presidente de la República, con la firma de todos los ministros, podrá declarar el Estado de Conmoción Interior, en toda la República o parte de ella, por término no mayor de noventa días, prorrogable hasta por dos períodos iguales, el segundo de los cuales requiere concepto previo y favorable del Senado de la República (República de Colombia, 2010, p. 107). 
No obstante, Agamben (2010a, 2014) muestra que después de la Primera Guerra Mundial las democracias occidentales son sometidas a la remoción de sus bases. Basta mencionar el permanente desplazamiento del poder Parlamentario por el poder Ejecutivo. Una forma de concentrar el poder político en un mismo eje de fuerzas y de capacidad de decisión. En conjunto, esto configura al 'estado de excepción' como el verdadero paradigma de la política occidental. Colombia no escapa a ese paradigma. Cepeda-Castro (2012) recurre a esta figura para explicar el problema endémico de las cárceles y mostrar su funcionamiento no como algo eventual, requerido de ajustes humanistas, sino como aquello que se repite, incesante, convirtiendo las cárceles en una zona donde se desecha lo que previamente la sociedad establece que debe desecharse ${ }^{3}$.

En el mismo debate, y circunscrita al caso de las mujeres, Gloria Stella Díaz-Ortiz (2012, p. 23) sostiene que “(...) más del $75 \%$ de la población de mujeres en las cárceles no ha concluido sus estudios secundarios; un $75 \%$ procede de la zona urbana frente al $24 \%$ de la zona rural, el $86 \%$ de las mujeres tienen hijos, el $79 \%$ son jefes de hogar y el $5 \%$ convive con su hijo dentro del centro de reclusión". Cifras que aumentan no solo por el colapso del sistema de administración de justicia, sino porque la delincuencia no decrece. Sumado a lo anterior, la institución carcelaria tampoco responde a las necesidades diferenciales de las poblaciones. En particular, si se refiere a las mujeres gestantes o que conviven con sus hijos menores de tres años en las cárceles, éstas requieren una atención médica especial y una alimentación adecuada con la etapa que atraviesan, si se asume que su bienestar guarda proporción con el que pueden ofrecer a sus hijos. Nótese lo siguiente:

(...) Me empezaron las contracciones. Entonces me llevaron a Sanidad y la enfermera me hizo un tacto y me dijo que era un cólico, que el bebé aún no se venía. A las doce de la noche continuaron las contracciones y yo le decía a mi niño que todavía no, que esperara mientras

3 Para un acercamiento reciente a la discusión sobre el poder soberano y el poder disciplinario, se sugiere el trabajo de Hernández-Jiménez (2013). amanecía y él como que obedecía y se quedaba quieto un ratico. No pude y volví donde la enfermera y ella me dijo que me iba a aplicar una Buscapina y yo le dije: ¡bruta! ¿Cómo se le ocurre? Me fui para la celda y me senté en un banquito con las piernas abiertas y fue el único modo de aguantar. Ya cuando llegó la hora de contarnos me bañé sentada con agua fría... No fui capaz de desayunar, porque era una salchicha con arepa fría. Pedí algo para tomar, porque tenía mucha sed y me dieron una gaseosa mezclada con agua para quitarle el gas ${ }^{4}$.

En contexto, esta cita es una manifestación de los procedimientos mediante los cuales se regula la atención de las mujeres gestantes dentro de la cárcel. En otras palabras, manifiesta el desconocimiento de las necesidades de una población en la que se exacerba la vulnerabilidad. Muchas de estas mujeres han sido trasladadas de las cárceles de sus lugares de origen. Dentro de las informantes de esta investigación, se encontraban mujeres de Venezuela, Chocó, Cauca, la Costa Caribe y de pueblos distantes a Medellín. Lo que es un obstáculo para que sus familiares, en especial sus hijos, puedan visitarlas, dar noticias de los suyos, mantener el vínculo familiar, ofrecer apoyo emocional y económico o encargarse de la salida quincenal de los niños que están con ellas en la cárcel; salida que hace parte del proceso de adaptación a lo que sería 'el afuera' definitivo después de la cárcel y de la separación de las madres. Probablemente, no sea del caso recurrir al cliché que orienta leer todo en 'perspectiva de género', como si ese concepto estuviese liberado de cualquier crítica (Halley, 2006, Hincapié-García, 2015). Sin embargo, el problema de la maternidad en la cárcel tiene que referirse a la división social del trabajo reproductivo (Carpenedo \& Nardi, 2013) y al lugar de las mujeres en esa división. De momento, basta con señalar que el sistema penitenciario y la institución carcelaria hacen gala de soberanía, toda vez que reclaman con empeño cuerpos que serán sometidos a múltiples intervenciones, diezmando la voluntad de crear

4 Dato tomado durante la entrevista realizada el día lunes 26 de enero de 2015. Informante 001. 
una vida buena tanto para hombres, mujeres, niños y niñas (Wolf, 2002, Nehamas, 2005).

En este punto, es necesario introducir la cuestión de la antropología pedagógica y la infancia para dar paso al problema del lenguaje y el encierro, a propósito de los niños encarcelados.

\section{Antropología pedagógica e infancia}

Enlaactualidad es común recurrira premisas antropológicas; en parte, por la inseguridad normativa al no encontrarse una respuesta plena a las preguntas: qué es el hombre y cuál es la esencia que le corresponde. Es decir, conforme escasea la seguridad en torno a la 'condición humana', se aumenta el registro de explicaciones antropológicas. Con la Ilustración (Aufklärung) y con desarrollo de la sociedad burguesa -que dará paso al capitalismo-, la antropología se va a constituir en el saber del hombre que se interroga por su perfeccionamiento (Wulf, 2008). Entretanto, la educación se propone como el medio a través del cual el hombre puede dar forma a ese perfeccionamiento. Por largo tiempo, la antropología dependió de los hallazgos de Kant. Sin embargo, Wulf (2008) afirma que Herder y Humboldt caracterizan la antropología en un sentido diferente. Según Kant (2004) la antropología es fisiológica y pragmática. Fisiológica, en tanto se ocupa de las regularidades del ser humano o, lo que es lo mismo, se ocupa de lo que la naturaleza hace de él. Pragmática, por lo cual reflexiona lo que el hombre hace de sí mismo como ser de libertad. Herder y Humboldt van a enfatizar mucho más en el carácter cultural e histórico del ser humano. De este modo, si Kant (2004) aparece como uno de los padres de la antropología, las consideraciones actuales de este saber le deben más a Herder y a Humboldt que al filósofo de Königsberg. Entre otras cosas porque el hombre kantiano, lejos de ser un hecho cultural e histórico, aparece como un ideal antropológico. Idea e ideal, si se permite la aclaración, tienen un vínculo importante en la filosofía de Kant. En específico, Kant (2003) afirma que una idea es el concepto de una perfección no encontrada en la experiencia; pero justo por referirse a una perfección orienta aquello que debe alcanzarse.
Por lo tanto, el hombre kantiano no es un hecho cultural e histórico, sino un ideal antropológico que se debe alcanzar mediante la educación.

Ahora bien, acercarse a Humboldt y a Herder conduce a consideraciones diferentes. Para el primero, según lo expone Wulf (2008), la antropología comparada debe investigar las peculiaridades de los distintos grupos humanos e intentar comprender, entre las contingencias y la variabilidad, el ideal de lo humano universal. Nótese, Kant postula dicho ideal y Humboldt (1997) lo busca. Herder (1982), a su vez, sostiene que la naturaleza ha sido para el hombre una madrastra despiadada, mientras que es una madre cariñosa con el resto de los animales: "A cada uno de éstos le ha dado cuanto necesita: sentidos para representar y representaciones convertidas en instinto, órganos para hablar, tantos cuantos necesita, y órganos para comprender ese lenguaje. En el hombre reina el mayor desequilibrio entre todo ello: sentidos y necesidades, facultades y círculo de acción que le espera, órganos y lenguaje" (Herder, 1982, p. 149). Al hombre le falta un nexo que le permita unir lo que en el animal está unido por naturaleza. Se puede plantear que lo que le falta al hombre es la formación. Carencia es el momento constitutivo de la existencia humana. Parafraseando a Mate (2008), el hombre debe hacerse cargo del hombre porque ha experimentado la ausencia de Dios -el nombre otro que toma la naturaleza-. En este punto dramático se puede situar la antropología pedagógica.

Para Runge-Peña y Muñoz-Gaviria (2005) el término compuesto antropología pedagógica, es útil para presentar un campo de reflexión, no establecido de manera absoluta, en el que se estudia el hombre como sub especie educacionis; esto no es otra cosa que el hombre como ser necesitado de educación -formable- ${ }^{5}$. Puede añadirse que la antropología pedagógica tiene un principio básico: el niño es un ser con una amplia capacidad para aprender; pero esta capacidad contrasta con una extrema necesidad

$5 \quad$ No está de más señalar lo que precisa Agamben (2010a): campo, después de Auschwitz, no puede retener el mismo significado que siempre se pretende. Habrá que recordar que "El campo es así tan sólo el lugar en que se realizó la más absoluta conditio inhumana". Por lo mismo, campo es aquello que siempre recuerda el exterminio. 
de cuidados y de ayudas pedagógicas por un largo período de tiempo. El niño comienza desde muy pequeño a formarse mediante los cuidados y la educación que otros le ofrecen para ingresar en el mundo cultural. En un primer momento son los padres o los cuidadores los que tienen la función de brindar al niño, a través de prescripciones y estímulos, los elementos formadores como el lenguaje, las costumbres y los usos de la moral, entre otros. Es decir, padres y cuidadores se alzan como lo otro de la formación al exponer para el niño los límites de lo permitido y lo permisible culturalmente. Los padres y los cuidadores constituyen "(...) una esfera de influencia pedagógica que envuelve como una segunda naturaleza al hombre" (Scheuerl, 1985, p. 13). Ahora, esa 'segunda naturaleza' es social e histórica. Esto es, lo natural viene a ser la influencia de la cultura en la formación del ser humano.

Se afirma que los padres y los cuidadores constituyen lo otro de la formación. Sin embargo, esto es incompleto si no se considera el papel de la escolarización en las sociedades modernas. Robertson (1982) indica que a lo largo de la historia lo general es que los padres se hacen cargo de la educación de los hijos o que, de manera privada, deleguen esa función. Esto comienza a cambiar en el siglo XIX con la aparición de un 'interés por los hijos ajenos'; este interés proviene de los poderes públicos en los cuales se produce un giro drástico que es el de pensar a los niños en sí mismos. Dada su vulnerabilidad, los niños están requeridos de una atención especial y, por lo tanto, son sujetos de observación por parte del Estado. No deja de llamar la atención que el pedido de observar a los niños debe remontarse a las prescripciones de Rousseau (2012). Si a este filósofo ilustrado se debe el reconocimiento de la infancia como un período de la vida que tiene valor por sí solo, también hay que relacionarlo con la idea pedagógica que reclama un no descanso de la mirada educadora (Runge-Peña, 1999). Todo un dispositivo de vigilancia pedagógica que no cesa de diagnosticar los equívocos de la formación, con atención especial a lo que se representa como peligrosidad social y disidencia sexual (Schérer, 1983, Foucault, 2002a y 2002b, Seoane, 2006, Laqueur, 2007,

Rev.latinoam.cienc.soc.niñez juv 15 (1): 59-70, 2017 http://revistalatinoamericanaumanizales.cinde.org.co DOI:10.11600/1692715x.1510226022016
Muñoz-Gaviria, 2007, Zambrano, 2012, Hincapié-García, 2012a). De igual modo, los padres y los cuidadores también son observados (Donzelot, 1990) ${ }^{6}$.

A la antropología pedagógica le corresponde, pues, un interés por las regularidades y las diferencias entre las demandas, expectativas y normas culturales que sostienen e instituyen el proceso formativo. Wulf (2008) nombra a Nietzsche y a Foucault, como dos grandes desafíos para el pensamiento antropológico y, por ende, para la antropología pedagógica. Con ellos se produce el fin del sueño antropológico o la posibilidad de encontrar al hombre igual a sí mismo en todo tiempo y lugar. Nietzsche denuncia como falsos

6 Incluso, referidos hacia un marco de referencia nacional, se puede citar un libro singular: El niño. Menores de edad (2002), firmado por Umaña-Luna. Este libro, que parece arrancado de preocupaciones anteriores a los años 80 , cuestiona las formas del Estado, entre ellas el derecho, incapaces de un sistema de observación eficiente de los niños y las familias en Colombia. Diagnostica el problema recurriendo a la pobreza, la desintegración familiar e, indirectamente, al socialismo, además de las 'disfunciones patológicas' y las deviaciones sexuales. Entre estas últimas, no podría faltar, la homosexualidad que, presentada al lado de la esquizofrenia, es una forma de modificación de los instintos. Curiosamente, más adelante Michel Foucault le servirá para continuar con su argumentación. La cuestión que se quiere señalar se abre en dos direcciones. La primera es teórica y versa sobre la reafirmación de eso que se está postulando sobre el dispositivo de vigilancia pedagógica que se toma los cuerpos de los niños y la familia como objetos observación (HincapiéGarcía \& Quintero-Idárraga, 2012). La segunda dirección tiene que ver con la creación del archivo, como enseñó a concebirlo Foucault (2006). Con ello obligar la mirada hacia un documento poco estudiado. Este se puede catalogar, solicitando cierta prudencia, como un acontecimiento discursivo bastante interesante, toda vez que irrumpe para insistir en la protección del niño y la familia, recurriendo a instrumentos analíticos abandonados ya, de cara a las transformaciones conceptuales en las ciencias sociales, los estudios culturales, los estudios de género y la teoría queer. No obstante, que un documento de esta naturaleza pueda ser publicado por un sello que lleva el nombre de la Universidad Nacional, indica que ni las preocupaciones ni los instrumentos analíticos han sido abandonados sino que, por el contrario, están prestos a reaparecer cuando la fascinación fetichista por los niños, las niñas y las familias reclaman vigilar y cazar los infractores que amenazan los preciados bienes que el fetichismo hace suyos. Edelman (2014) afirma que toda vez que los discursos reaccionarios se apropian de los términos infancia y familia, están apuntando hacia su fijación fetichista heteronormativa. Fijación que está cargada eróticamente por una fantasía de preservarse a sí mismos y a los de su raza y clase (Berlant, 2011). Así, cuando el derecho habla de 'nuestros niños' y 'nuestras familias', no se refiere a otra cosa que al lugar erótico y fantasioso donde esperan vivir aquellos a los que el derecho bien representa. Edelman (2014) acierta: en la fantasía es el único lugar donde el fetichista quiere vivir. En este caso, sobran los discursos liberales sobre la pluralidad. Ya se ha dicho, en el lugar de la fantasía reaccionaria solamente caben los de la misma raza y clase. Por eso, no pocas veces las batallas en nombre de los niños y las familias, en realidad, son batallas contra los pobres, los homosexuales y contra lo que amenace con otras posibilidades culturales (Foucault, 1996). 
y contrarios a la honestidad los predicados definitivos sobre el hombre y Foucault demuestra que lo que puede decirse del hombre es histórico. Esto tiene varias consecuencias. La primera es que la antropología tiene que asumir que en la cultura todo es formado. La segunda refiere que la educación, y por tanto la reflexión pedagógica, es inseparable de la antropología. La tercera consecuencia indica que la antropología pedagógica, al ser interpelada por la desconfianza en los ideales universales y en las perspectivas de unificación antropológica, por fuerza se convierte en antropología histórica. Expuesto así, esta antropología no puede observar la infancia intentando la clave del perfeccionamiento del hombre, sino desnudando los dispositivos que hacen violencia al cuerpo de los niños en nombre de ideales formativos.

\section{Lenguaje y encierro}

El lenguaje aparece, aproximadamente, en el primer año de la vida de los niños. Surge en la infancia temprana y a partir de allí participa de todas las actividades del hombre. De este modo, el lenguaje se antoja tan evidente que nunca se repara suficiente en el lugar determinante que tiene en la formación de los seres humanos. No pocas veces su definición es confusa y dispar. Empero, es posible establecer ciertas dimensiones comunes. Belinchón-Carmona, Rivière e Igoa-González (1992) identifican tres de ellas. La primera hace referencia al hecho de que el lenguaje sea comprendido como un sistema de signos lingüísticos, con una organización interna que posibilita descripciones estructurales o formales. $\mathrm{La}$ segunda plantea que la adquisición y el uso del lenguaje significan la posibilidad de relacionar, interactuar e intervenir en el medio social. Finalmente, la tercera dimensión refiere que el lenguaje se inscribe a través de formas específicas de conducta individual y social.

Concentrándose en las dos últimas dimensiones, habría que precisar algunos aspectos. La infancia temprana, un período que se extiende hasta los tres años, es concebida por Vygotski (1996) como un momento evolutivo en el que el niño se aferra a la situación. Esto es, lo que el niño puede saber depende de todo lo externo que lo convoca. De hecho, Vygotski señala que, en general, para los niños la realidad se compone de lo que pueden abarcar con la mirada y allí radica uno de los aspectos que más influye en su formación. Si se examina bien, no se guardan recuerdos muy organizados de este período, lo cual se debe a la limitada participación de la memoria, y sus procesos, en la actividad de la consciencia durante la infancia temprana. En este momento evolutivo, pensar “(...) significa orientarse en las relaciones afectivas dadas y actuar de acuerdo con la situación externa que se percibe. En la edad mencionada impera la percepción visual-directa, afectivamente matizada, que se transforma de inmediato en acción" (Vygotski, 1996 , p. 345). Esto informa que los niños no organizan los datos que provienen de su medio por la función de procesos desarrollados y diferenciados, plenamente, como la atención, la memoria y el pensamiento. Más bien, se está indicando la preeminencia de dos aspectos: la percepción visual y la cualidad afectiva de la situación.

Puede advertirse que las relaciones que el niño crea consigo mismo, los seres humanos, el mundo y los objetos, están vinculadas a las situaciones externas y dependen de las capacidades que el niño ha desarrollado para crear dichas relaciones. Llevando este planteamiento al registro antropológico de Londoño-Blair (2008): el hombre aprende los elementos de la vida cotidiana por medio de la actividad social. Enfatizando en las relaciones de los niños en la infancia temprana, éstas serán condicionantes para las posteriores relaciones que se crearán en otros momentos evolutivos. Este punto, además de lo indicado por Vygotski, ha sido estudiado por Freud $(2004,2012)$. Así, las relaciones en la infancia temprana se constituyen en la base de las relaciones sociales.

Hay que establecer una necesaria proximidad entre las relaciones sociales $\mathrm{y}$ lenguaje. Vygotski (1996, p. 305) afirma que la aparición de este último contradice un poco lo que ha referido sobre la infancia temprana orientada por la percepción visual: "(...) el lenguaje quebranta de inmediato la unidad sensomotora, incide en la dependencia 
situacional del niño". Los elementos nuevos que se ofrecen en la complejidad hilvanada entre percepción y lenguaje, alteran las relaciones del niño con todo su entorno; lo que incluye que las relaciones sociales también sean modificadas. El núcleo aquí planteado es que el lenguaje se constituye en el elemento principal en este período porque modifica todas las relaciones existentes para el niño.

Ahora bien, el lenguaje no es una actividad personal. Las capacidades que los infantes desarrollan, la oportunidad que el lenguaje les da para participar, apropiarse y transformar su mundo, tienen su origen y realización en las relaciones con los otros; sustancialmente con los adultos. Aquí es claro que la infancia no puede entenderse solamente como un momento evolutivo. Es también una situación social e históricamente creada. Para Vygotski (1996, pp. 356-357) son los adultos "(...) los que impulsan al niño a una nueva vía de generalización, al dominio del lenguaje, etc. Y el dominio del lenguaje lleva a una configuración nueva de toda la estructura de la conciencia". Aunado a lo anterior, se puede relacionar dos importantes aspectos discutidos por Chaves-Castaño (2011). El primero de ellos informa que en el proceso de la evolución el lenguaje modifica radicalmente la dimensión psicológica del ser humano. El segundo aspecto refiere que la mente humana no solo se desarrolla por los procesos de adaptación al entorno sino también a través de las interacciones sociales. Resulta clave concentrar estos dos últimos aspectos en el problema referido a los niños en la cárcel, debido a que las condiciones exteriores diseñadas para ellos en las instituciones carcelarias son adecuadas en apariencia; se habla de las instalaciones y los espacios para su cuidado. Sin embargo, el problema se muestra en su complejidad cuando se analizan los términos mediante los cuales los niños crean sus relaciones interpersonales en las cárceles, para lo cual necesitan aprender y dominar el sistema de signos y símbolos que dan forma a estas instituciones.

Es relevante el problema social y la responsabilidad moral que debe estar en la base de un tema poco estudiado: el desarrollo del lenguaje de los niños en la cárcel.

Rev.latinoam.cienc.soc.niñez juv 15 (1): 59-70, 2017 http://revistalatinoamericanaumanizales.cinde.org.co DOI: $10.11600 / 1692715 x .1510226022016$

\section{Resultados y conclusiones}

Una de las preocupaciones expresadas por las madres del Complejo Carcelario y Penitenciario Pedregal-Coped Medellín, estriba en el desarrollo del lenguaje de sus hijos. Señalan que después de las salidas quincenales a las que tienen derecho los niños y las niñas, estos regresan más activos y con recursos lingüísticos más amplios. Aspecto que se relaciona con el tipo de interacciones propiciadas por las familias de acogida. No obstante, lo anterior se diluye en los días siguientes. Las madres perciben que sus hijos se hacen más rebeldes, susceptibles al llanto $\mathrm{y}$, algunos, llegan a expresar su rechazo por regresar a la cárcel. Si en un principio la esfera social ofrecida por las familias de acogida produce el efecto de una ampliación de los recursos interpersonales y simbólicos de los niños, este efecto no se conserva porque la estructura carcelaria no permite el reforzamiento que lo ha hecho posible 7 . No es extraño, entonces, que el lenguaje de los niños parezca estereotipado y un tanto reproductor de los estilos de relación lingüística que se establecen en la cárcel. Aspecto que se relaciona con el tipo de juegos que reproducen la vida social de la que participan en el encierro.

Del mismo modo, un aspecto observado tiene que ver con la capacidad de los niños para resolver conflictos interpersonales entre ellos. Por ejemplo, las cuidadoras refieren que los niños y las niñas que tienen a cargo, tienden a resolver los conflictos entre ellos recurriendo al llanto, los ataques de ira, los golpes o la autoagresión. Para las cuidadoras, los niños y las niñas de la cárcel tendrían menos recursos simbólicos para resolver su malestar en comparación con los niños y niñas que tienen condiciones de socialización -formacióndiferentes a las establecidas en la cárcel ${ }^{8}$.

Otros resultados encontrados por esta investigación señalan que el empobrecimiento del lenguaje se remite a la interacción social mediada entre rejas que, continuamente, separa

Dato tomado durante entrevista realizada el día miércoles 18 de marzo de 2015. Informante 005.

8 Dato tomado durante entrevista realizada el día miércoles 17 de junio de 2015. Informante 007. 
un espacio de otro, al horario que comparten las presas y los niños -el horario del niño es el horario del preso-, a la regulación singular del tiempo que pueden compartir los hijos con sus madres, a la vigilancia a la que es sometida la relación madre e hijo y al saber compartido de que el encierro de los niños no es otra cosa que el primero, aunque no el último, de sus ingresos a la cárcel. Las madres encarceladas asumen que las posibilidades de que sus hijos sean cuerpos encerrados gran parte de sus vidas exceden las posibilidades que tendrán otros niños ${ }^{9}$.

Aunado a los datos empíricos que se pueden exponer, es importante relacionar la investigación de Lejarraga et al. (2011). En esta se encontró, para el contexto argentino, que los niños encarcelados, entre los dos y tres años, crean conductas imitativas referidas al lenguaje, los estilos comunicativos y las formas interpersonales que se acentúan en la cárcel. Además de ello, los instrumentos de medición les permitieron a los investigadores, postular que la cárcel representa un espacio que vulnera la vida emocional de los niños. A su juicio, la historia personal de las madres - maltrato, pobre nivel educativo y deprivación socio-familiary la misma organización carcelaria, afectan las posibilidades vitales para el crecimiento y el desarrollo. No obstante, esto no significa que los niños deban ser separados de sus madres porque el mismo estudio demostró que, a diferencia de las que optaron por entregar al cuidado de otros sus hijos después del nacimiento, las madres que conservaron a sus hijos durante el encierro, tras cumplir la condena continuaron a cargo de ellos.

Finalmente, y para volver a plantear el supuesto de este trabajo, Rivière (1985) sostiene que es Vygotski el que introduce el problema de la 'estructura semántica de la conciencia'. Esta consciencia se forma por una compleja relación con los signos, las palabras y la función de las interacciones sociales en la formación de los niños. En este sentido, la consciencia no preexiste o no se forma en soledad. Al contrario, las condiciones de posibilidad de su desarrollo dependen de la vida social; esto es, la cultura de la cual se hace participes a los niños. La

9 Dato tomado durante entrevista realizada el día miércoles 24 de junio de 2015. Informante 008 . consciencia no es un reflejo directo de las cosas como si un tipo de preeminencia empírica se impusiera. Más bien, si de algún tipo de reflejo se habla, vale aclarar que éste es la mediación a través de las categorías y los conceptos que establecen 'formas de unidad' (Rivière, 1985). Si la consciencia fuera un simple reflejo no se podría hablar de los significados construidos por los hombres a propósito de las relaciones consigo mismos, los otros, el mundo y los objetos. Lo que se está planteando implica que las relaciones del ser humano no son meramente reflejos. Estas relaciones están mediadas por el lenguaje y por las condiciones que hicieron posible su desarrollo en la infancia. En otras palabras, si el ser humano crea lo que es significativo para sí a través del lenguaje, no resta más que experimentar horror por las condiciones empobrecidas que se ofrecen para el desarrollo del lenguaje de los niños en las cárceles. Se tiene entonces que para estos niños, la cárcel -entendida como aquello que mina las condiciones para la creación de una vida buena-, es la excepción que les espera como norma.

\section{Lista de referencias}

Agamben, G. (2006). Lo abierto. El hombre y el animal. Buenos Aires: Adriana Hidalgo.

Agamben, G. (2010a). Homo sacer. El poder soberano y la nuda vida. Valencia: PreTextos.

Agamben, G. (2010b). Medios sin fin. Notas sobre la política. Valencia: Pre-Textos.

Agamben, G. (2014). Estado de excepción. Buenos Aires: Adriana Hidalgo.

Ariès, P. (1987). El niño y la vida familiar en el antiguo régimen. Madrid: Taurus.

Badinter, E. (1981). ¿Existe el amor maternal? Historia del amor maternal. Siglos XVII al $X X$. Barcelona: Paidós.

Belinchón-Carmona, M., Rivière, Á. \& Igoa-González, J. (1992). Psicología del lenguaje. Investigación y teoría. Madrid: Trotta.

Benjamin, W. (2010). Hacia una crítica de la violencia. Obras. Libro II/vol. 1. Madrid: Abada.

Rev.latinoam.cienc.soc.niñez juv 15 (1): 59-70, 2017 http://revistalatinoamericanaumanizales.cinde.org.co DOI: $10.11600 / 1692715 x .1510226022016$ 
Benjamin, W. (2012). Sobre el concepto de historia. Obras. Libro I/vol. 2. Madrid: Abada.

Berlant, L. (2011). El corazón de la nación. Ensayos sobre política y sentimentalismo. México, D. F.: Fondo de Cultura Económica.

Carpenedo, M. \& Nardi, H. (2013). Mulheres Brasileiras na divisão internacional do trabalho reprodutivo: construindo subjetividade(s). Revista de estudios sociales, 45, pp. 96-109. Doi: http://dx.doi. org/10.7440/res55.2016.03

Cepeda-Castro, I. (2012). Intervención en la Sesión Ordinaria del día miércoles 15 de agosto de 2012. Cámara de Representantes. Recuperado de: www.camara.gov.co/ portal2011/gestor.../6840-2012-gac-850acta-pl-2012-08-15pdf

Chaves-Castaño, L. (2011). La inteligencia social y sus implicaciones en la evolución de la mente. Revista de psicología, 3 (1), pp. 73-86.

Díaz-Ortiz, G. (2012). Intervención en la Sesión Ordinaria del día miércoles 15 de agosto de 2012. Cámara de Representantes. Recuperado de: www.camara.gov.co/ portal2011/gestor.../6840-2012-gac-850acta-pl-2012-08-15pdf

Donzelot, J. (1990). La policía de las familias. Valencia: Pre-textos.

Edelman, L. (2014). No al futuro. La teoría queer y la pulsión de muerte. Barcelona: Egales.

Foucault, M. (1982). La imposible prisión: Debate con Michel Foucault. Barcelona: Anagrama.

Foucault, M. (1996). Sex, Power and the Politics of Identity. Interview by Bob Gallagher and Alexander Wilson. In S. Lotringer (ed.) Foucault Live. Collected Interviews 1961-1984, (pp. 382-390). New York: Semiotext(e).

Foucault, M. (2002a). Historia de la sexualidad. 1. La voluntad de saber. Buenos Aires: Siglo XXI.

Foucault, M. (2002b). Los anormales. Curso en el Collège de France (1974 1975). México, D. F.: Fondo de Cultura Económica.
Foucault, M. (2006). La Arqueología del saber. México, D. F.: Siglo XXI.

Freud, S. (2004). Sexualidad infantil y neurosis. Madrid: Alianza.

Freud, S. (2012). Tres ensayos sobre teoría sexual y otros escritos. Madrid: Alianza.

Halley, J. (2006). Split Decisions: How and Why to Take a Break from Feminism. New Jersey: Princeton University Press.

Herder, J. G. (1982). Ensayo sobre el origen del lenguaje. En Obras selectas. Madrid: Alfaguara.

Hernández-Jiménez, N. (2013). Poder soberano $\mathrm{y}$ poder disciplinario. La codificación desde una visión foucaultiana. Revista de estudios sociales, 48, pp. 139-150. Doi: http://dx.doi.org/10.7440/res55.2016.03

Hincapié-García, A. (2012a). El sexo como verdad. Morfología corporal ambigua y expectativas culturales en torno al cuerpo. En A. K. Runge-Peña \& B. EscobarGarcía (comps.) Educación, eugenesia y progreso: Biopoder y gubernamentalidad en Colombia, (pp. 153-182). Medellín: Unaula.

Hincapié-García, A. (2015). Revisiones críticas al concepto de género. Apuntes para la teoría social contemporánea. Universitas Humanística, 79, pp. 15-40. Doi: http:// dx.doi.org/10.11144/Javeriana.UH79.rccg

Hincapié-García, A. \& Quintero-Idárraga, S. (2012). Cuerpos sometidos, sujetos educados. Apuntes para una interpretación de las luchas discursivas por la construcción de la educación sexual en Colombia. Revista Latinoamericana de Ciencias Sociales, Niñez y Juventud, 10 (1), pp. 93-105. Doi: 10.11600/1692715x.1321300514.

Humboldt, W. (1997). Escritos sobre filosofia de la historia. Madrid: Tecnos.

Kant, I. (2003). Pedagogía. Madrid: Akal.

Kant, I. (2004). Antropología en sentido pragmático. Madrid: Alianza.

Kant, I. (2006). Crítica de la razón pura. México, D. F.: Taurus.

Laqueur, T. (2007). Sexo solitario. Una historia cultural de la masturbación. Buenos Aires: Fondo de Cultura Económica.

Lejarraga, H., Berardi, C., Ortale, S., Contreras, M. M., Sanjurjo, A., Lejarraga, C. \& 
Rodríguez, L. (2011). Crecimiento, desarrollo, integración social y prácticas de crianza en niños que viven con sus madres en prisión. Archivos Argentinos de Pediatría, 109 (6), pp.485-491.

Levi, P. (2012). Trilogía de Auschwitz. Barcelona: Océano.

Londoño-Blair, A. (2008). El cuerpo limpio. Higiene corporal en Medellín, 1880-1950. Medellín: Universidad de Antioquia.

Martyniuk, C. (2011). Jirones de piel, ágape insumiso. Estética, epistemología y normatividad. Buenos Aires: Prometeo Libros.

Mate, M. R. (2008). La herencia del olvido. Ensayos en torno a la razón comprensiva. Madrid: Errata Naturae.

Muñoz-Gaviria, D. (2007). Concepciones de niñez y juventud en las pedagogías católicas de principios del siglo XX en Colombia. Revista Latinoamericana de Ciencias Sociales, Niñez y Juventud, 5 (2), pp. 841-857. Doi:10.11600/169271 $5 x .1321300514$.

Nehamas, A. (2005). El arte de vivir. Reflexiones socráticas de Platón a Foucault. Valencia: Pre-Textos.

Ossa-López, M. (2016). La cárcel en Colombia. Espacio para la venganza y la reincidencia. Medellín: Unaula.

Pedraza, Z. (2007). El trabajo infantil en clave colonial. Consideraciones históricoantropológicas. Nómadas, 26, pp. 80-90.

Prior-Olmos, Á. (coord.) (2002). Nuevos métodos en ciencias humanas. Barcelona: Anthropos.

República de Colombia (2010). Constitución Politica de Colombia. Actualizada con los actos legislativos hasta 2010. Bogotá, D. C.: Consejo Superior de la Judicatura, Sala Administrativa, Centro de Documentación Judicial (Cendoj), Biblioteca Enrique Low Murtra.

Rivière, Á. (1985). La Psicología de Vigotsky. Madrid: Visor.

Robertson, P. (1982). El hogar como nido: la infancia de la clase media en la Europa del siglo XIX. En Ll. de Mause (ed.) Historia de la infancia, (pp. 444-471). Madrid: Alianza.
Rousseau, J-J. (2012). Emilio o de la educación. México, D. F.: Porrúa.

Runge-Peña, A. K. (1999). La paradoja del reconocimiento de la niñez desde la pedagogía. Reflexiones en torno al eco rousseauniano. Revista Educación y Pedagogía, 23-24, pp. 65-86.

Runge-Peña, A. K. \& Muñoz-Gaviria, D. A. (2005). Mundo de la vida, espacios pedagógicos, espacios escolares $\mathrm{y}$ ex-centricidad humana: reflexiones antropológico-pedagógicas y sociofenomenológicas. Revista Latinoamericana de Ciencias Sociales, Niñez y Juventud, 3 (2), pp. 1-21. Doi:10.11600/169271 $5 x .1321300514$.

Schérer, R. (1983). La pedagogía pervertida. Barcelona: Laertes.

Scheuerl, H. (1985). Antropología pedagógica. Introducción histórica. Barcelona: Herder.

Seoane, J.-B. (2006). El placer y la norma. Genealogía de la educación sexual en la España contemporánea. Orígenes (18801920). Barcelona: Octaedro.

Toro-Vanegas, (2007). Situación carcelaria en Colombia. En Observatorio Latinoamericano de Prisiones (ed.) $A$ la sombra de la sociedad. Situación penitenciaria en Latinoamérica, (pp. 133-137). Caracas: Observatorio Latinoamericano de Prisiones.

Umaña-Luna, E. (2002). El niño. Menores de edad. Investigación y análisis interdisciplinarios. Bogotá, D. C.: Universidad Nacional de Colombia.

Vygotski, L.-S. (1996). La infancia temprana. Obras Escogidas IV. Psicología Infantil. Madrid: Antonio Machado.

Wolf, U. (2002). La filosofía y la cuestión de la vida buena. Madrid: Síntesis.

Wulf, C. (2008). Antropología. Historia, cultura, filosofía. Barcelona: Anthropos.

Zambrano, I. (2012). Miradas científico anormales a la infancia en situación de calle: José Gutiérrez o los imaginarios sociales modernos. Revista Colombiana de Educación, 63, pp. 273-288. 